\title{
Estimation of the number of Anisakis larvae in commercial fish using a descriptive model based on real-time PCR
}

\begin{tabular}{|r|l|}
\hline Journal: & Journal of the Science of Food and Agriculture \\
\hline Manuscript ID & JSFA-20-0303.R2 \\
\hline Wiley - Manuscript type: & Research Article \\
\hline Complete List of Authors: & $\begin{array}{l}\text { Godínez González, Carla Samanta; University of Barcelona, Department } \\
\text { of Biology, Health and Environment, Faculty of Pharmacy and Food } \\
\text { Sciences } \\
\text { Roca-Gerones, Xavier; University of Barcelona, Department of Biology, } \\
\text { Health and Environment, Faculty of Pharmacy and Food Sciences } \\
\text { Montoliu, Isabel; University of Barcelona, Department of Biology, Health } \\
\text { and Environment, Faculty of Pharmacy and Food Sciences } \\
\text { Fisa, Roser; University of Barcelona, Department of Biology, Health and } \\
\text { Environment, Faculty of Pharmacy and Food Sciences }\end{array}$ \\
\hline Key Words: & $\begin{array}{l}\text { Anisakis, Foodborne parasites, Food safety, Larval quantification method, } \\
\text { Molecular technique }\end{array}$ \\
\hline &
\end{tabular}

\section{SCHOLARONE' \\ Manuscripts}


1 Estimation of the number of Anisakis larvae in commercial fish using a descriptive model based on real-time PCR

6 Carla Godínez-González ${ }^{1}$, Xavier Roca-Geronès ${ }^{1}$, Isabel Montoliu ${ }^{1}$, Roser Fisa ${ }^{1}$

7

$8 \quad{ }^{1}$ Laboratory of Parasitology, Department of Biology, Health and Environment, Faculty of

9 Pharmacy and Food Sciences, University of Barcelona, Barcelona, Catalonia, Spain 10

11 Corresponding author: Roser Fisa

12 rfisa@ub.edu

13 Laboratory of Parasitology, Department of Biology, Health and Environment, Faculty of

14 Pharmacy and Food Sciences, University of Barcelona, Av. Joan XXIII, 27-31, 08028

15 Barcelona, Catalonia, Spain.

16

17

18 Declarations of interest: none 


\section{ABSTRACT}

24 BACKGROUND

25 Seafood parasitization by Anisakis (Anisakidae) larvae has been reported in most of the

26 oceans and seas worldwide. The presence of these nematodes in commonly consumed fish

27 represents a potential hazard for consumers as they can provoke gastrointestinal symptoms

28 and allergic reactions. In the present work, the capacity of a SYBR Green qPCR protocol to

29 quantify Anisakis larvae in commercial fish was evaluated using experimentally spiked

30 samples with different numbers (0-50) of $A$. simplex third-stage larvae (L3). To verify the

31 agreement of the obtained results, 25 naturally infected fish specimens of Atlantic blue

32 whiting underwent a parallel visual inspection.

\section{RESULTS}

34 The logarithmic behavior of the Cq data obtained from the experimentally spiked samples

35 allowed the development of a descriptive mathematical model that correlates the Cq value

36 with the number of Anisakis larvae $\left(\mathrm{R}^{2}=0.9908, \mathrm{CV}=2.37 \%\right)$. In the commercial blue

37 whiting specimens there was a high correlation between the results of the molecular

38 technique and the visual inspection $\left(\mathrm{R}^{2}=0.9912\right)$; the Bland-Altman analysis showed that

$3994 \%$ of the differences were within the limits of agreement ( -4.98 and 6.68$)$, indicating the

40 reliability of the descriptive mathematical model based on the SYBR Green qPCR

41 technique.

\section{CONCLUSION}

43 The descriptive function presented based on the SYBR Green qPCR assay is promising as a

44 sensitive and accurate tool for measuring the Anisakis larval load in commercial fish, with a

45 potential application not only in the food industry but also in prevention programs for

46 public health. 

47 KEYWORDS
$48 \quad$ Anisakis
$49 \quad$ Foodborne parasites
50 Food safety
51 Larval quantification method
52 Molecular technique

54

55

56

57

58

59

60

61

62

63

64

65

66

67

68

69

\section{INTRODUCTION}

Foodborne parasites are considered important pathogens as they can cause disease and economic loss worldwide; humans can be exposed to these parasites through the food supply chain (Trevisan et al., 2019). Seafood parasitation by larvae of anisakid nematodes has been reported in most oceans and seas worldwide (D'amico et al., 2014). The presence of these parasites in commercial fish is a potential hazard for consumers as they can provoke gastrointestinal symptoms and allergic reactions. The sibling species Anisakis simplex sensu stricto and $A$. pegreffii, which belong to the $A$. simplex sensu lato complex, are the most common causative agents of human clinical cases of anisakiasis and allergic reactions in Europe and Asia (Mattiucci et al., 2018). In addition, clinical cases of Pseudoterranova spp. and Contracaecum spp. have been reported in the Southern hemisphere (Shamsi and Butcher, 2011; Weitzel et al., 2015). Other ascaridoid larvae highly prevalent in fish are the non-pathogenic Hysterothylacium species (Raphidascarididae), which can be misidentified as Anisakis spp. because of morphological similarities (Simsek et al., 2018). 
70 The clinical manifestations of gastro-intestinal anisakiasis, caused by living larvae,

71 include epigastric pain, nausea, vomiting and diarrhea (Baird et al., 2014). Allergic

72 reactions, caused by live and dead larvae, are characterized by urticaria, angioedema,

73 bronchospasm and even anaphylactic shock (Audicana et al., 2002). Studies suggest $A$.

74 simplex (s.1.) is a major hidden producer of allergic incidents associated with food

75 (Anıbarro et al., 2007).

76

77 Although Anisakis larvae mostly infect visceral organs, they can also penetrate the

78 musculature and accumulate in edible parts of fish. The presence of these nematode larvae

79 in fish flesh is important not only from the health point of view but also because of its

80 economic implications, since it decreases fish quality and provokes consumer rejection

81 (Cipriani et al., 2016). Visual inspection is currently mandatory in fish quality control and

82 several types of techniques have been applied to improve the visual detection of these

83 parasites, including candling, pressing, digestion and UV illumination, (Gómez-Morales

84 et al., 2018; Guardone et al., 2016; Levsen et al., 2005). Enzyme-linked immunosorbent

85 assays (ELISA) have been developed for the quantification of Anisakis proteins using

86 polyclonal antibodies (Werner et al., 2011). More recently, proteomics methods based on

87 liquid chromatography tandem mass spectrometry (LC-MS/MS) have been applied to

88 detect Anisakis proteins in fish and fish matrices (Fæste et al., 2016). Parallel reaction

89 monitoring (PRM) mass spectrometry has also been used to detect anisakid-specific peptide

90 biomarkers in commonly consumed fish (Carrera et al., 2016).

91

92 New strategies for the fast detection of fish-borne parasites are molecular-based techniques

93 that can also be applied to processed food products regardless of thermal treatments, such 
as canning and freezing, or mechanical handling, such as sieving and chopping. Polymerase chain reaction (PCR) has been used to identify anisakid species isolated from commonly consumed fish; the first and second internal transcribed spacers (ITS-1 and ITS-2,

97 respectively) of nuclear ribosomal DNA have proved to be useful for genotypic identification (Mattiucci et al., 2018). Real-time PCR (qPCR) has been used to detect Anisakis DNA in experimentally inoculated fish (Lopez and Pardo, 2010) and naturally infested commercial fish samples, as well as in different types of commercial fish-derived food, providing highly sensitive results (Mossali et al., 2010). The quantitative capacity of

102 qPCR methods applied in food with probes or fluorescent dyes such as SYBR Green 103 (Rodríguez-Lázaro and Hernández, 2013), avoiding the use of expensive labeled probes, 104 can facilitate the detection and quantification of Anisakis larvae in fish and fish-derived 105 food. In the present work, we evaluated the ability of an Anisakis specific SYBR Green 106 qPCR protocol to accurately quantify Anisakis larvae in commercial fish, presenting a 107 descriptive model that can express the relationship between molecular results and the 108 number of larvae present.

\section{MATERIALS AND METHODS}

\subsection{Experimental fish samples}

112 A total of 570 A. simplex (s.1.) third-stage (L3) larvae isolated from viscera and belly flaps 113 of specimens of Atlantic blue whiting (Micromesistius poutassou), purchased in retail 114 stores in Barcelona, were used for contaminating fish samples. Larvae were identified 115 morphologically (Koie, 1993; Petter and Maillard, 1988) and stored in physiological 116 solution at $4{ }^{\circ} \mathrm{C}$ until use. 
118 Fillets of hake approximately $80 \mathrm{~g}$ in weight (Merluccius merluccius), purchased in retail

119 stores, were checked for Anisakis absence by visual inspection, which was performed by

120 dissection and observation under a stereomicroscope (Leica MZ6) using incident and

121 transmission light. The hake specimens came from the Mediterranean Spanish coast, an

122 area of low parasitation by Anisakis (Barcala et al., 2018). In addition, fillets from the fish

123 tail were used, in which the parasite is not as likely (Roca-Geronès et al., 2020). Samples of

$12415 \mathrm{~g}$ of Anisakis-free fillets were experimentally contaminated with different numbers of $A$.

125 simplex (s.1.) L3 larvae (0, 1, 2, 3, 4, 5, 10, 15, 20, 25, 30, 35, 40, 45 and 50); four fillets for

126 each larval number tested were used. Samples were homogenized in a Stomacher-400

127 (Seward, UK) with $100 \mathrm{ml}$ of lysis solution (100 mM Tris $\mathrm{HCl} \mathrm{pH}$ 8.0, $5 \mathrm{mM}$ EDTA pH

$1288.0,0.2 \% \mathrm{SDS}, 200 \mathrm{mM} \mathrm{NaCl}$, and $80 \mathrm{mg} / \mathrm{L}$ proteinase $\mathrm{K}$ ) for $60 \mathrm{~min}$. The samples were 129 kept rotating at $350 \mathrm{rpm}$ for 60 minutes at $55^{\circ} \mathrm{C}$.

130

$131 \quad 2.2$ Commercial fish samples analyzed

132 Twenty-five specimens of Atlantic blue whiting, purchased in retail stores in Barcelona,

133 were studied. Each fish was divided in four parts: visceral organs including mesenteries,

134 and anterior ventral, anterior dorsal and posterior musculature. Fish parts were dissected

135 under a stereomicroscope, and all the larvae observed were morphologically identified and

136 counted. Each fish part, together with the larvae detected in it, was homogenized as

137 described for the experimental Anisakis-spiked samples, and in the case of viscera $50 \mathrm{ml}$ of

138 lysis solution was added.

139

140

\subsection{DNA extraction}


141 Genomic DNA purification was performed with the Wizard Genomic DNA Purification Kit

142 (Promega, Spain). DNA was extracted from $200 \mu \mathrm{L}$ fish homogenates. Samples were

143 mixed with $600 \mu \mathrm{L}$ of Nuclei Lysis Solution and $17.5 \mu \mathrm{L}$ of $20 \mathrm{mg} / \mathrm{ml}$ Proteinase K (Roche

144 Diagnostics, Spain) and incubated overnight at $55^{\circ} \mathrm{C}$. DNA was precipitated with ethanol

145 at $70 \%$ (Sigma-Aldrich, Spain), and resuspended in the rehydration solution (10mM Tris-

$146 \mathrm{HCl}, 1 \mathrm{mM}$ EDTA). Two independent DNA extractions were performed for each fish

147 homogenate. The quality of the DNA extraction was assessed by absorbance at $260 \mathrm{~nm}$

148 using a ND-1000 spectrophotometer (NanoDrop Technologies, USA). Purified DNA was

149 stored at $-20^{\circ} \mathrm{C}$ until qPCR analysis.

150

$151 \quad 2.4$ SYBR Green qPCR

152 A pair of primers, targeting a fragment of the mitochondrial cytochrome $c$ oxidase subunit

153 II gene were used, which have been previously validated as specific for Anisakis (Lopez

154 and Pardo, 2010).The molecular analysis was performed using a high sensitive SYBR

155 Green qPCR assay (Godínez-González et al., 2017). Reaction mixtures were prepared in

156384 optical well plates containing $5 \mu \mathrm{L}$ of $1 \times$ SYBR Green Master Mix (Roche

157 Diagnostics, Spain), $0.6 \mu \mathrm{L}$ of $300 \mathrm{nM}$ of forward and reverse primers, and $2.5 \mu \mathrm{L}$ of DNA.

158 A. simplex (s.l.) larval DNA and molecular biology-grade water (Sigma-Aldrich, Spain)

159 were used as positive and negative controls, respectively. Amplifications were carried out

160 in the thermocycler LightCycler 480 Instrument II (Roche Diagnostics, Germany),

161 programmed to hold $50{ }^{\circ} \mathrm{C}$ for $2 \mathrm{~min}, 95^{\circ} \mathrm{C}$ for $10 \mathrm{~min}$, followed by 40 cycles of $95^{\circ} \mathrm{C}$ for

$16215 \mathrm{~s}$ and $65^{\circ} \mathrm{C}$ for $1 \mathrm{~min}$. The melting curve analysis was as follows: $95^{\circ} \mathrm{C}$ for $1 \mathrm{~min}, 40$ 
$163{ }^{\circ} \mathrm{C}$ for $1 \mathrm{~min}, 65^{\circ} \mathrm{C}$ for $1 \mathrm{~s}$ and then an increase of $1{ }^{\circ} \mathrm{C} / \mathrm{s}$ to $95^{\circ} \mathrm{C}$ for $30 \mathrm{~s}$. All analyses

164 were performed in duplicate.

165

166 Results were expressed as quantification cycle $(\mathrm{Cq})$ values; all samples with a $\mathrm{Cq} \geq 35$

167 were considered negative. The specificity was ascertained by comparing the melting

168 temperatures $(\mathrm{Tm})$ of the amplification products from studied samples to that of the

169 positive control $\left(\mathrm{Tm}=76^{\circ} \mathrm{C}\right)$.

170

$171 \quad 2.5$ Statistical analysis

172 A univariate analysis of variance (ANOVA) was used to obtain different groups of $\mathrm{Cq}$

173 values associated with a determinate number of Anisakis larvae in the experimentally

174 spiked samples. A Bland-Altman analysis was performed to assess the agreement between

175 the two quantitative detection methods, visual and SYBR Green qPCR (Bland and Altman,

176 1999). Limits of agreement were calculated using the mean and standard deviation of the

177 differences between the two measurements. All statistical analyses were carried out using

178 SAS 9.4 software (SAS Institute, USA).

179

180 3. RESULTS

$181 \quad 3.1$ Anisakis SYBR Green qPCR study on experimentally contaminated fish samples

182 The molecular analysis of experimentally spiked hake samples revealed a logarithmic 183 relationship between the number of $A$. simplex (s.1.) larvae present and the Cq values, with 184 results ranging from 24.3 to 17.7 , corresponding to 1 and 50 larvae, respectively. These 185 findings allowed us to develop a descriptive function expressing the experimental results $(\mathrm{Cq}$ $\left.186=-1.529 x+24.109 ; \mathrm{R}^{2}=0.9908\right)($ Figure 1$)$. According to the analysis of variance of the $\mathrm{Cq}$ 
187 values, six distinct groups (A to F) related to the number of larvae were discernable $(\mathrm{P}<0.05)$ :

188 group A, with a Cq of 35, corresponded to the absence of Anisakis larvae in the sample; group

189 B corresponded to the presence of 1-3 larvae; group C, 4-10 larvae; group D, 11-25 larvae;

190 group E, 26-40 larvae; and group F to more than 40 larvae. The assay precision, expressed 191 as the coefficient of variation (CV), ranged from $0.95 \%$ to $2.37 \%$, indicating the technique 192 was highly reproducible (Table 1).

193

194

\subsection{Visual inspection and SYBR Green qPCR study on commercial fish}

195 The visual inspection of 25 Atlantic blue whiting resulted in the detection and identification 196 of Anisakis and Hysterothylacium larvae, coinfection being observed in three specimens 197 and exclusive Hysterothylacium infection in two. A total of 834 Anisakis larvae were 198 identified as A. simplex (s.1.), ranging from 0 to 112 with a mean intensity of 41.7 per fish.

199 On the other hand, 29 Hysterothylacium aduncum larvae were observed, ranging from 2 to 20010 with a mean intensity of 5.8 larvae per fish infected with this parasite.

201

202 The Anisakis load in the different parts of fish was studied in parallel by visual inspection 203 and with SYBR Green qPCR. The molecular results expressed as the number of Anisakis 204 larval equivalents calculated using the descriptive function (NLE) and the number of larvae 205 observed by visual inspection (NLV) are indicated in Table 2. The correlation analysis 206 showed a high concordance between both methods regarding the number of larvae in the 207 analyzed samples $\left(\mathrm{R}^{2}=0.9912\right)$ (Figure $\left.2 \mathrm{~A}\right)$. Although experimentally the largest number of 208 larvae tested was 50, in naturally infested fish the descriptive function was able to estimate 209 a much larger number (up to 100) of larval equivalents, as in the case of the visceral organs 
210 of one of the analyzed specimens (NLE=119; NLV=112) (Table 2). Furthermore, Bland-

211 Altman analysis showed that $94 \%$ of the differences were within the limits of agreement (-

2124.98 and 6.68) (Figure 2B). In the two specimens of blue whiting infected only by

213 Hysterothylacium, the Cq value for each fish part was 35, showing that the presence of this

214 raphidascaridid did not interfere with the quantification of Anisakis larvae.

215

216 The results obtained from the different parts of the fish analyzed were classified among the

217 six groups (A-F) according to the number of larvae of Anisakis (Table 2). The visceral

218 organs were the most parasitized, with 20/25 infected fish (80\% 95\% CI 60-92); the larvae

219 being distributed in all groups (A-F), with high percentages in groups E (24\%, $95 \%$ CI 12-43)

220 and F (20\% 95\% CI 9-39), those with the highest parasite load. The anterior ventral

221 musculature showed 18/25 parasitized fish (72\% $95 \%$ CI 52-86) with a great variability: $28 \%$

$222\left({ }_{95 \%} \mathrm{CI} 14-28\right)$ of the samples corresponded to group A, $\left.28 \%{ }_{95 \%} \mathrm{CI} 14-28\right)$ to group B, $16 \%$

$223\left({ }_{95 \%} \mathrm{CI} 6-35\right)$ to group D, 12\% $\left.{ }_{95 \%} \mathrm{CI} 4-29\right)$ to group C, and $16 \%\left({ }_{95 \%} \mathrm{CI} 6-35\right)$ to group E.

224 The anterior dorsal musculature presented Anisakis in only 8/25 fish (32\% CI 17-52),

225 containing a low number of larvae: $68 \%\left({ }_{95 \%} \mathrm{CI} 48-83\right)$ of the samples were classified as

226 group A, 24\% $\left.{ }_{95 \%} \mathrm{CI} 12-43\right)$ as group B and $8 \%\left({ }_{95 \%} \mathrm{CI} 1-26\right)$ as group E. The posterior

227 musculature, with 6/25 parasitized fish (24\% 95\%CI 11-44) showed the lowest larval

228 presence, as Anisakis were detected only in 24\% (95\% CI 12-43) of the samples belonging to

229 group B.

230

231 DISCUSSION

232 The European Food Safety Authority reported approximately 20,000 clinical cases of 233 anisakiasis worldwide up to 2010 , with more than $90 \%$ from Japan. In Europe, Spain is 
234 considered to have the highest incidence of this disease (EFSA, 2010). The two sibling

235 species $A$. simplex (s.s.) and $A$. pegreffii have been described as the main etiological

236 agents of human anisakiasis and allergic reactions; however, some studies have reported

237 the possible risk of invasive infection caused by $A$. physeteris and A. paggiae (Romero et

238 al., 2013). These data highlight the need to validate reliable techniques for the detection

239 and quantification of Anisakis in consumed fish and fish-derived food and thus help prevent

240 anisakiasis and allergic incidents.

241

242 The qPCR technique is a promising tool to determine the presence of foodborne pathogens

243 because of its precision, speed, cleanliness and safety (Rodríguez-Lázaro and Hernández,

244 2013). In this study, the descriptive function obtained after SYBR Green qPCR assays

245 allowed to quantify the number of larvae of $A$. simplex (s.l) in naturally infected fish, which

246 would include the sibling species $A$. simplex (s.s.) and A. pegreffii. Other species of

247 Anisakis such as $A$. physeteris could also be detected using this qPCR technique, although

248 its different amplification behaviour, with two-log Cq lateness from the two sibling species,

249 would not led to apply the proposed descriptive function (Godínez-González et al., 2017).

251 In the present work, the application of the descriptive function obtained allowed an

252 estimation of the number of Anisakis larvae in the analyzed blue whiting specimens, and

253 the results were closely correlated with those obtained by visual inspection. In the fishery

254 sector, over the last 50 years, the visual inspection has been widely used, but the results

255 obtained may vary according to the operator training and lighting conditions or because of

256 low standardization (Guardone et al., 2016; Llarena-Reino et al., 2012). Currently, the

257 artificial enzymatic digestion procedure by CODEX (STAN 244-2004) is the recommended 
258 procedure for anisakids detection and counting in certain fish species and commercial

259 displays (Llarena-Reino et al., 2013). Alternative techniques such as UV-press (Karl and

260 Leinemann, 1993) are increasingly carried out; however, samples should be analyzed after

261 thawing and factors as the presence of skin and the fat content can reduce the efficiency and

262 sensitivity (Yang et al., 2013). The molecular technique described in our study has great

263 sensitivity and specificity and allows the detection of Anisakis larvae embedded in the

264 muscle, as well as in the two previous techniques, which may go unnoticed in a visual

265 inspection (Stormo et al., 2007). Sample processing is simple and is done without removing

266 the fish skin, which does not interfere in the results. The specificity for Anisakis of the

267 primers used ensures that the presence of larvae from other common and non-pathogenic

268 species in the same area, such as those of Hysterothylacium that are morphologically

269 similar, does not interfere with the results. The possibility of automatizing the molecular

270 process, would allow the analysis of large amount of samples in a short period of time and

271 with reduced staff.

272

273 The prevalence of Anisakis larvae and infection intensity in wild fish vary according to

274 species, fishing area, season and individual characteristics of the fish (Mattiucci et al., 2018;

275 Roca-Geronès et al., 2020). As in the vast majority of marine fish, blue whiting tend to

276 accumulate Anisakis larvae in their visceral organs (Madrid et al., 2012; Roca-Geronès et al.,

277 2020), which were the most parasitized part of the fish in this study. However, larval

278 migration to the flesh also constitutes an important source of infection, reflected in the high

279 number of larvae detected in the anterior ventral musculature. The parasitic load in the

280 musculature decreases towards the posterior end of the fish, and the anterior dorsal and

281 posterior musculature are considered the safest parts for human consumption because of the 
282 absence or low number of larvae detected (Cipriani et al., 2015). Other studies using visual

283 inspection have reported similar Anisakis larval distribution in this host species in specimens 284 from different fishing areas (Chía et al., 2010; Gómez-Mateos et al., 2016, Roca-Geronès et 285 al., 2020).

286

287 Several studies worldwide have shown that sensitization to Anisakis allergens varied widely 288 in prevalence (up to $81 \%$ ) in patients that have presented allergic reactions to seafood 289 (Mazzucco et al., 2018). There is a risk of nonviable Anisakis material inducing allergic 290 reactions (Moneo et al, 2005). Different techniques that destroy the larvae cannot provide 291 effective protection against allergic reactions, as residual parasite presence remains after 292 applying food processing treatments such as cooking, canning or freezing (Rodríguez-

293 Mahillo et al., 2010; Tejada et al., 2015). The SYBR Green qPCR technique used to 294 optimize the model described amplifies a small fragment of the target region, which is 295 stable under thermal food processing. Thereby, extremely fragmented DNA could anneal 296 the primers, permitting the analysis of highly processed samples (Godínez-González et al., 297 2019).

298

299 Authorities in food safety and fishing facilities currently employ detection methods for 300 Anisakis control; however, measurement scales of parasitic load have not been established, 301 and rejection criteria and limits of detection have not been standardized for use by food 302 handlers (Commission Regulation (EC) No 2074/2005; FDA 2011). The function described 303 could be applied to optimize an automated molecular platform for the control of a large 304 number of samples and batches of commercial fish, as well as fish-derived foods. The 305 classification of batches of fish according to their parasitic load by molecular methods 
306 could orientate decision-making regarding usage, thus reducing the risk of accidental

307 ingestion of Anisakis larvae. Finally, the descriptive function presented based on the SYBR

308 Green qPCR assay is promising as a sensitive and accurate tool for measuring the Anisakis

309 larval load in commercial fish, with a potential application not only in the food industry but 310 also in prevention programs for public health, helping to improve the safety and quality of

311 fishery products and consumer protection.

312

313 ACKNOWLEDGEMENTS

314 The authors thank Lucy Brzoska for her invaluable advice on the English preparation of the 315 manuscript.

317 FUNDING

318 This work was supported by the Generalitat de Catalunya 2017 SGR Project (1008) and

319 CONACYT-Becas México scholarship number 383879.

\section{REFERENCES}

321 Anibarro, M,. Seoane, B., Mugica, F., 2007. Involvement of hidden allergens in food 322 allergic reactions. J. Invest. Allergol. Clin. Immunol. 17, 168-172.

323 Audicana, M. T., Ansotegui, I. J., de Corres, L. F., Kennedy, M. W., 2002. Anisakis

324 simplex: Dangerous dead and alive? Trends Parasitol. 18, 20-25.

325 Barcala, E., Ramilo, A., Ortega, N., Picó, G., Abollo, E., Pascual, S., Muñoz, P., 2018.

326 Occurrence of Anisakis and Hysterothylacium larvae in commercial fish from Balearic

327 Sea (Western Mediterranean Sea). Parasitol. Res. 117, 4003-4012.

328 PMID: 30327920 
329 Bland, J.M., Altman D.G., 1999. Measuring agreement in method comparison studies. Stat. 330 Methods Med. Res. 8,135-160.

331 Baird, F.J., Gasser, R.B., Jabar, A., Lopata, A.L., 2014. Food borne anisakiasis and allergy. 332 Mol. Cell. Probes. 28, 167-174.

333 Carrera, M., Gallardo, J. M., Pascual, S., Gonzalez A., Medina, I., 2016. Protein biomarker 334 discovery and fast monitoring for the identification and detection of Anisakids by 335 336 parallel reaction monitoring (PRM) mass spectrometry. J. Proteomics 142, 130-137.

Chía, N., Romero, M.C., Polo-Vico, R., Gómez-Mateos, M., Abattouy, N., Valero, A., 2010. Estudio epidemiológico de Anisakis tipo I en la bacaladilla (Micromesistius poutassou) del noroeste de España. Ars Pharm. 51, 829-834.

Cipriani, P., Smaldone, G., Acerra, V., D'Angelo, L., Anastasio, A., Bellisario, B., Palma, G., Nascetti, G., Mattiucci, S., 2015. Genetic identification and distribution of the parasitic larvae of Anisakis pegreffii and A. simplex (s. s.) in European hake Merluccius merluccius from the Tyrrhenian Sea and Spanish Atlantic coast: implications for food safety. Int. J. Food Microbiol. 198, 1-8.

Cipriani, P., Acerra, V., Bellisario, B., Sbaraglia, G.L., Cheleschi, R., Nascetti, G., Mattiucci, S., 2016. Larval migration of the zoonotic parasite Anisakis pegreffii (Nematoda: Anisakidae) in European anchovy, Engraulis encrasicolus: Implications to seafood safety. Food Control. 59, 148-157.

Commission Regulation (EC) No 2074/2005 Laying down implementing measures for certain products under regulation (EC) No. 853/2004 of the European parliament and of the council and for the organization of official control under regulation (EC) No. $854 / 2004$ of the European parliament and of the council and regulation (EC) No. $882 / 2004$ of the European parliament and of the council, derogating from regulation 
353

354

355

356

357

358

359

360

361

362

363

364

365

366

367

368

369

370

371

372

373

374

375

376

(EC) No. 852/2004 of the European parliament and of the council and amending regulations (EC) No.853/2004 and (EC) No. 854/2004. OJEU L338:27-59.

D'amico, P., Malandra, R., Costanzo, F., Castigliego, L., Guidi, A., Gianfaldoni, D., Armani, A., 2014. Evolution of the Anisakis risk management in the European and Italian context. Food Res. Int. 64, 348-362.

EFSA, 2010. Scientific opinion on risk assessment of parasites in fishery products. Panel on Biological Hazards (BIOHAZ), European Food Safety Authority (EFSA). EFSA J. $8,4,1543-1634$.

Fæste, C., Jonscher, K., Dooper, M., Egge-Jacobsen, W., Moen, A., Daschner, A., Egaas, E. y Christians, U., 2014. Characterization of potential novel allergens in the fish parasite Anisakis. Eu Pa Open Proteomics. 4, 140-155.

Fæste, C., Moen, A., Schniedewind, B., Anonsen, J., Klawitter, J., Christians, U., 2016. Development of liquid chromatography-tandem mass spectrometry methods for the quantitation of Anisakis simplex proteins in fish, J. Chromatogr. A 1432:58-72.

Food and Drug Administration (FDA), 2011. Fish and fishery products hazards and controls guidance.

http://www.fda.gov/Food/GuidanceRegulation/GuidanceDocumentsRegulatoryInforma tio/Seafood/ucm2018426.htm.

Godínez-González, C., Roca-Geronès, X., Cancino-Faure, B., Montoliu, I., Fisa, R., 2017. Quantitative SYBR Green qPCR technique for the detection of the nematode parasite Anisakis in commercial fish-derived food. Int. J. Food Microbiol. 261, 89-94.

Godínez-González, C., Roca-Geronès, X., Montoliu, I., Fisa, R., 2019. Importance of using complex matrices in the standardization of molecular techniques for the control of foodborne parasites. J. Agric. Food Chem. 67, 11279-11280. 
377 Gómez-Mateos, M., Valero, A., Morales-Yuste, M., Martín-Sánchez, J., 2016. Molecular

378 epidemiology and risk factors for Anisakis simplex (s.l.) infection in blue whiting

379 (Micromesistius poutassou) in a confluence zone of the Atlantic and Mediterranean:

380 Differences between A. simplex (s.s.) and A. pegreffii. Int. J. Food Microbiol. 232,

$381 \quad 111-116$

382 Gómez-Morales, M.A., Martinez Castro, C., Lalle, M., Fernandez, R., Patrizio Pezzotti, P., 383 Abollo, E., Pozio, E., 2018. UV-press method versus artificial digestion method to 384 detect Anisakidae L3 in fish fillets: comparative study and suitability for the industry. $385 \quad$ Fish. Res. 202, 22-28.

386 Guardone, L., Malandra, R., Costanzo, F., Castigliego, L., Tinacci, L., Gianfaldoni, D., 387 Guidi, A., Armani, A., 2016. Assessment of a sampling plan based on visual inspection 388 for the detection of Anisakid larvae in fresh anchovies (Engraulis encrasicolus). A first 389 step to- wards official validation? Food Anal. Methods. 9, 1418-1427.

390 Karl, H., Leinemann, M., 1993. A fast and quantitative detection method for nematodes in 391 fish fillets and fishery products. Arch. Lebensmittelhyg 44, 105-128.

392 Koie, M., 1993. Aspects of the life cycle and morphology of Hysterothylacium aduncum 393 (Rudolphi, 1802) (Nematoda, Ascaridoidea, Anisakidae). Can. J. Zool. 71, 1289-1296. 394 Lee W.J., Seo D.J., Oh H., Jeon, S.B., Jung, D., Choi, C., 2016. Simultaneous detection and 395 prevalence of allergens in Anisakis species isolated from marine fishes. J. Food Prot. $396 \quad 79,789-94$.

397 Levsen, A., Lunestad, B.T., Berland, B., 2005. Low detection efficiency of candling as a 398 commonly recommended inspection method for nematode larvae in the flesh of 399 pelagic fish. J. Food Prot. 68, 828-832.

400 Llarena-Reino, M., González, Á.F., Vello, C., Outeirino, L., Pascual, S., 2012. The 
401

402

403

404

405

406

407

408

409

410

411

412

413

414

415

416

417

418

419

420

421

422

423

accuracy of visual inspection for preventing risk of Anisakis spp. infection in unprocessed fish. Food Control. 23, 54-58.

Llarena-Reino, M., Piñeiro, C., Antonio, J., Outeriño, L., Vello, C., González, A., Pascual, S., 2013. Optimization of the pepsin digestion method for anisakids inspection in the fishing industry. Vet Parasitol. 191, 276-283.

Lopez, I., Pardo, M.A., 2010. Evaluation of a real-time polymerase chain reaction (PCR) assay for detection of Anisakis simplex parasite as a food-borne allergen source in seafood products. J. Agric. Food Chem. 58, 1469-1477.

Mazzucco, W., Raia, D., Marotta, C., Costa, A., Ferrantelli, V., Vitale, F., Casuccio, A., 2018. Anisakis sensitization in different population groups and public health impact: a systematic review. Plos One. 13, 9, e0203671.

Madrid, E., Galán-Puchades, M.T., Fuentes, M.V., 2012. Risk analysis ofhuman anisakidosis through the consumption of the blue whiting, Micromesistius poutassou, sold at Spanish supermarkets. Foodborne Pathog. Dis. 9, 934-938.

Mattiucci, S., Cipriani, P., Levsen, A., Paoletti, M., Nascetti, G., 2018. Molecular epidemiology of Anisakis and anisakiasis: an ecological and evolutionary road map. Adv. Parasitol. 99, 93-263.

Moneo, I., Caballero, M.L., González-Muñoz M., Rodríguez-Mahillo,I., Rodríguez-Perez R., Silva, A., 2005. Isolation of a heat-resistant allergen from the fish parasite Anisakis simplex. Parasitol. Res. 96, 285-289.

Mossali, C., Palermo, S., Capra, E., Piccolo, G., Botti, S., Bandi, C., D’Amelio, S., Giuffra, E., 2010. Sensitive detection and quantification of anisakid parasite residues in food products. Foodborne Pathog. Dis. 7, 391-397. 
424 Petter, A.J., Maillard, C., 1988. Larves d'Ascarides parasites de Poissons en Méditerranée 425 occidentale. Bull. Mus. Hist. Nat. 10, 347-369.

426 Roca-Geronès, X., Segovia, M., Godínez-González, C., Fisa, R., Montoliu, I., 2020.

427 Anisakis and Hysterothylacium species in Mediterranean and North-East Atlantic

428 fishes commonly consumed in Spain: Epidemiological, molecular and morphometric 429 discriminant analysis. Int. J. Food Microbiol. 325:108642.

430 Rodríguez-Lázaro, D., Hernández, R., 2013. Real-time PCR in food science: Introduction. 431 Curr. Issues Mol. Biol. 15, 25-38.

432 Rodríguez-Mahillo, I., Gonzalez-Muñoz, M., De las Heras, C., Moneo, I., 2010.

433 Quantification of Anisakis simplex allergens in fresh, long-term frozen, and cooked fish 434 muscle. Foodborne Pathog. Dis. 7, 8, 967-973.

435 Romero, M., Valero, A., Navarro-Moll, M.C., Martín-Sánchez, J., 2013. Experimental 436 comparison of pathogenic potential of two sibling species Anisakis simplex (s. s.) and 437 Anisakis pegreffii in Wistar rat. Trop. Med. Int. Health 18, 979-984.

438 Shamsi, S., Butcher, A.R., 2011. First report of human anisakidosis in Australia. Med. J. $439 \quad$ Aust. 194, 4, 199-200.

440 Simsek, E., Ciloglu, A., Yildirim, A., Pekmezci, G.Z., 2018. Identification and Molecular 441 Characterization of Hysterothylacium (Nematoda: Raphidascarididae) larvae in bogue 442 443

444 Stormo, S., Sivertsen, A., Heia, K., Nilsen, H., Elvevoll, E., 2007. Effects of single 445 wavelength selection for anisakid roundworm larvae detection through multispectral 446 imaging. J. Food Prot. 70, 8, 1890-1895. 
447 Tejada, M., Olivares, F., De las Heras, C., Careche, M., Solas, M., García, M., Fernández,

448 A., Mendizábal, A., Navas, A., Rodríguez-Mahillo, I., González-Muñoz, M., 2015.

449 Antigenicity of Anisakis simplex (s.s.) L3 in parasitized fish after heating conditions

450 used in the canning processing. J. Sci. Food. Agric. 95, 922-927.

451 Trevisan, C., Torgerson, P., Robertson, L., 2019. Foodborne Parasites in Europe: present

452 status and future trends. Trends Parasitol. 35, 9, 695-703.

453 Weitzel, T., Sugiyama, H., Yamasaki, H., Ramirez, C., Rosas, R., Mercado, M., 2015.

454 Human infections with Pseudoterranova cattani nematodes, Chile. Emerg. Infect.

455 Diseases. 21, 1874-1875.

456 Werner, M.T., Fæste, C.K., Levsen, A., Egaas, E., 2011. A quantitative sandwich ELISA

457 for the detection of Anisakis simplex protein in seafood. Eur. Food Res. Technol. 232, $458 \quad 157-166$.

459 Yang, X., Rui, N., Hong, L., Cui, D., Jianxin, S., Limin, C., 2013. Detection of Anisakid

460 Larvae in Cod Fillets by UV Fluorescent Imaging Based on Principal Component

$461 \quad$ Analysis and Gray Value Analysis. J. Food Prot. 76, 1288-1292. 
Table1. Results of SYBR Green qPCR applied to hake samples experimentally contaminated with determinate numbers of Anisakis larvae.

\begin{tabular}{ccc}
\hline $\begin{array}{c}\text { Number of } \\
\text { Anisakis larvae }\end{array}$ & $\begin{array}{c}\mathbf{C q}^{* \dagger} \\
(\mathbf{9 5 \%} \mathbf{C I})\end{array}$ & $\begin{array}{c}\mathbf{C V} \\
\mathbf{( \% )}\end{array}$ \\
\hline 0 & $35.0(33.9-35.6)^{\mathbf{A}}$ & 1.53 \\
\hline 1 & $24.3(23.4-25.2)^{\mathbf{B}}$ & 2.37 \\
\hline 2 & $22.9(22.4-23.7)^{\mathbf{B}}$ & 2.14 \\
\hline 3 & $22.5(22.3-22.7)^{\mathbf{B}}$ & 0.97 \\
\hline 4 & $21.4(21.1-21.6)^{\mathbf{C}}$ & 1.24 \\
\hline 5 & $21.5(21.3-21.9)^{\mathbf{C}}$ & 1.41 \\
\hline 10 & $21.7(21.2-21.9)^{\mathbf{C}}$ & 1.66 \\
\hline 15 & $20.0(19.7-20.3)^{\mathbf{D}}$ & 2.05 \\
\hline 20 & $20.2(19.9-20.6)^{\mathbf{D}}$ & 1.07 \\
\hline 25 & $19.8(19.7-20.1)^{\mathbf{D}}$ & 0.95 \\
\hline 30 & $19.1(18.9-19.3)^{\mathbf{E}}$ & 1.73 \\
\hline 35 & $18.7(18.4-19.0)^{\mathbf{E}}$ & 0.96 \\
\hline 40 & $18.5(18.2-18.8)^{\mathbf{E}}$ & 1.64 \\
\hline 45 & $17.6(17.2-17.9)^{\mathbf{F}}$ & 1.55 \\
\hline 50 & $17.7(17.4-17.8)^{\mathbf{F}}$ & 1.13 \\
\hline
\end{tabular}

$\mathrm{Cq}$, mean quantification cycle value; $\mathrm{CI}$, confidence interval; $\mathrm{CV}$, coefficient of variation Letters A-F indicate statistical groups detected relating $\mathrm{Cq}$ values to a determinate number of larvae.

${ }^{*}$ Four DNA extractions were amplified by qPCR in duplicate

$\dagger$ Values with the same letter are not significantly different (Tukey, $\mathrm{P}<0.05$ ) 
Table 2. Comparison of the number of Anisakis larvae obtained by the descriptive function and visual inspection in the 25 naturally infected blue whiting analyzed and distribution of the different fish parts among the groups $(\mathrm{A}-\mathrm{F})$.

\begin{tabular}{|c|c|c|c|c|c|c|c|}
\hline & & Group A & Group B & Group C & Group D & Group E & Group F \\
\hline \multirow[t]{4}{*}{ Visceral organs } & $\mathrm{Cq} \pm \mathrm{SD}^{*}$ & $35.0 \pm 0.0$ & $23.37 \pm 0.4$ & $21.1 \pm 0.6$ & $19.5 \pm 0.2$ & $19.0 \pm 0.1$ & $17.1 \pm 1.1$ \\
\hline & NLE & $0(0-0)$ & $3(2-3)$ & $(6-10)^{\dagger}$ & $21(21-25)$ & $29(27-33)$ & $43(43-119)$ \\
\hline & NLV & $0(0-0)$ & $2(2-3)$ & $(8-11)^{\dagger}$ & $23(22-24)$ & $28(26-35)$ & $45(45-112)$ \\
\hline & $\mathrm{N}^{\circ}$ of fish & 5 & 3 & 2 & 4 & 6 & 5 \\
\hline \multirow{4}{*}{$\begin{array}{l}\text { Anteroventral } \\
\text { musculature }\end{array}$} & $\mathrm{Cq} \pm \mathrm{SD}^{*}$ & $35.0 \pm 0.0$ & $23.6 \pm 0.9$ & $21.9 \pm 0.3$ & $20.25 \pm 0.2$ & $19.1 \pm 0.3$ & \\
\hline & NLE & $0(0-0)$ & $1(1-3)$ & $4(4-6)$ & $15(12-15)$ & $28(28-40)$ & \\
\hline & NLV & $0(0-0)$ & $1(1-3)$ & $4(3-5)$ & $12(12-16)$ & $26(25-39)$ & \\
\hline & $\mathrm{N}^{\circ}$ of fish & 7 & 7 & 4 & 3 & 4 & \\
\hline \multirow{4}{*}{$\begin{array}{l}\text { Anterodorsal } \\
\text { musculature }\end{array}$} & $\mathrm{Cq} \pm \mathrm{SD}^{*}$ & $35.0 \pm 0.0$ & $23.5 \pm 0.3$ & & & $19.3 \pm 0.02$ & \\
\hline & NLE & $0(0-0)$ & $1(1-2)$ & & & $(26-27)^{\dagger}$ & \\
\hline & NLV & $0(0-0)$ & $1(1-2)$ & & & $(25-28)^{\dagger}$ & \\
\hline & $\mathrm{N}^{\circ}$ of fish & 17 & 6 & & & 2 & \\
\hline \multirow{4}{*}{$\begin{array}{c}\text { Posterior } \\
\text { musculature }\end{array}$} & $\mathrm{Cq} \pm \mathrm{SD}^{*}$ & $35.0 \pm 0.0$ & $23.9 \pm 0.6$ & & & & \\
\hline & NLE & $0(0-0)$ & $1(1-2)$ & & & & \\
\hline & NLV & $0(0-0)$ & $1(1-2)$ & & & & \\
\hline & $\mathrm{N}^{\circ}$ of fish & 19 & 6 & & & & \\
\hline
\end{tabular}

Group A-F indicate the groups described by SYBR Green qPCR related to the number of larvae: A, no larvae presence; B, 1-3; C, 4-10, D; 11-25; E, 26-40; F, >40

NLE, number of Anisakis larval equivalents calculated using the descriptive function; NLV, number of larvae observed by visual inspection; Cq, mean quantification cycle value; SD, standard deviation.

Number of larvae expressed as Mode (Range).

${ }^{*}$ Two DNA extractions from each sample were amplified by qPCR in duplicate

$\uparrow$ Bimodal group 
Figure 1. Descriptive function obtained by plotting the mean Cq values obtained by SYBR Green qPCR with respect to the number of Anisakis larvae (from 0 to 50), expressed as natural logarithm $(\mathrm{Ln})$, in experimentally contaminated fish samples. The correlation coefficient $\left(\mathrm{R}^{2}\right)$ is indicated.

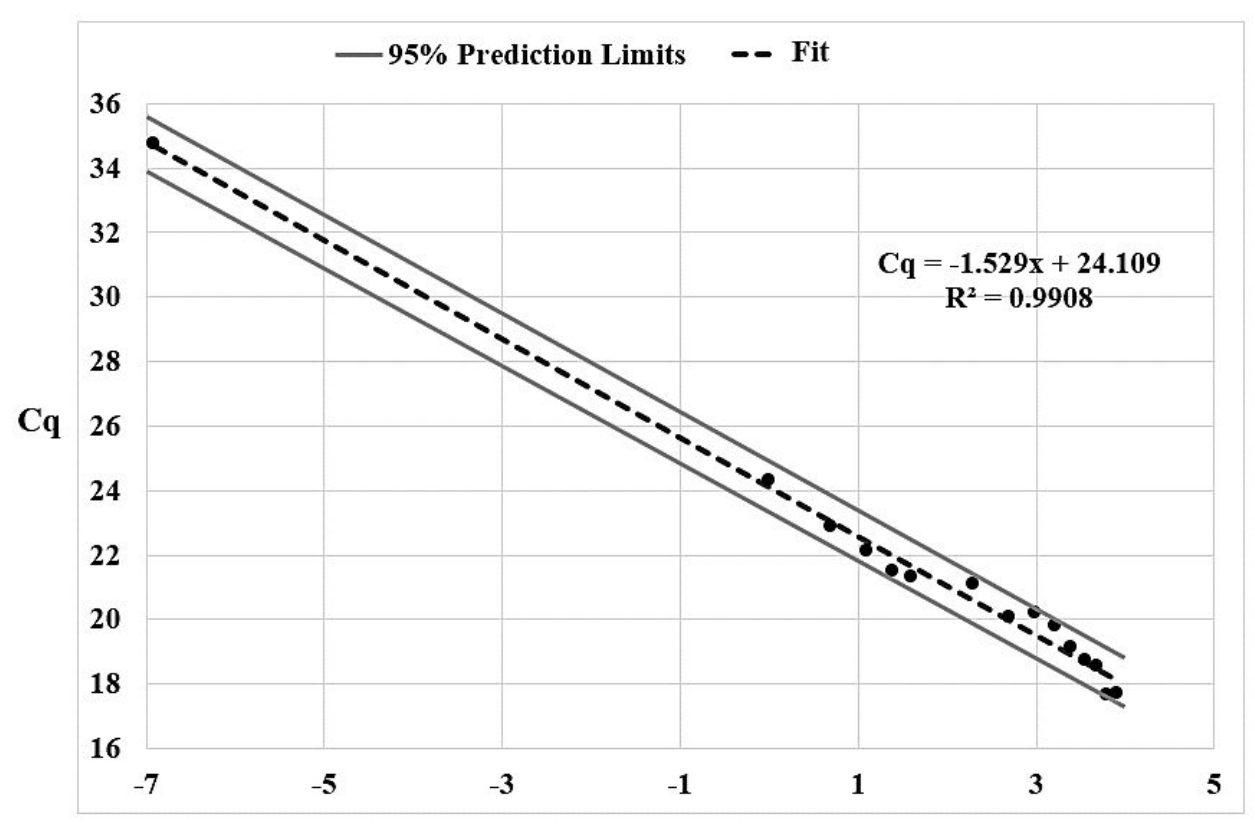

Ln Anisakis larvae number 
Figure 2. Correlation (A) and Bland-Altman (B) plots showing the concordance between the results obtained by the descriptive function and visual inspection for Anisakis larval quantification in the 25 naturally infected blue whiting analyzed. The correlation coefficient $\left(\mathrm{R}^{2}\right)$ and $95 \%$ limits of agreement $(\mathrm{LoA})$ are indicated.
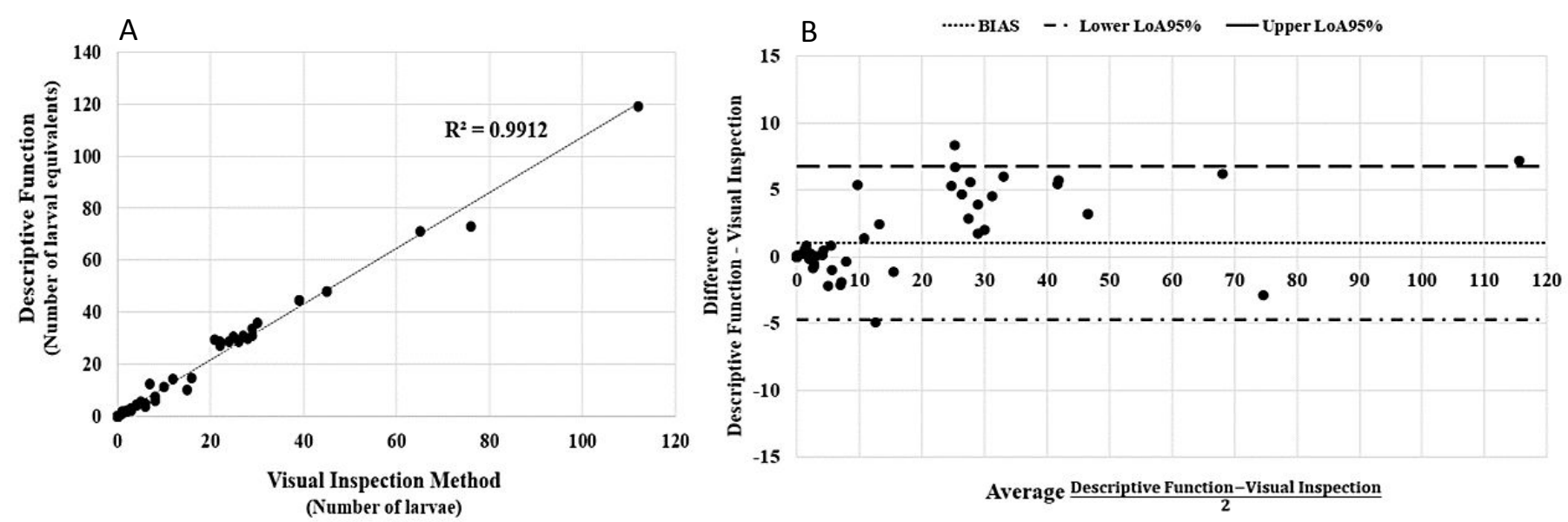